\title{
Endogenous Patterns of Activity Are Required for the Maturation of a Motor Network
}

\author{
Sarah J. Crisp, Jan Felix Evers, and Michael Bate \\ Department of Zoology, University of Cambridge, Downing Street, Cambridge CB2 3EJ, United Kingdom
}

\begin{abstract}
Many parts of the nervous system become active before development is complete, including the embryonic spinal cord. Remarkably, although the subject has been debated for over a century (Harrison, 1904), it is still unclear whether such activity is required for normal development of motor circuitry. In Drosophila, embryonic motor output is initially poorly organized, and coordinated crawling-like behavior gradually emerges over the subsequent phase of development. We show that reversibly blocking synaptic transmission during this phase severely delays the first appearance of coordinated movements. When we interfere with the pattern of neuronal firing during this period, coordination is also delayed or blocked. We conclude that there is a period during which endogenous patterns of neuronal activity are required for the normal development of motor circuits in Drosophila.
\end{abstract}

\section{Introduction}

Most embryos move before they are fully mature, demonstrating that motor circuits, like many sensory networks, are active before birth. While in sensory systems there is evidence that this activity is required to determine final patterns of connectivity (Stafford et al., 2009), it remains unclear whether there is a requirement for activity-based modifications during the formation of motor circuits. Early experiments indicated that a normally functioning motor network could be assembled without previous activity in the circuits concerned, suggesting that adequate connectivity can be successfully defined by an activity-independent system of growth and connection (Haverkamp, 1986; Haverkamp and Oppenheim, 1986). In contrast, recent work with central networks driving limb movements in the mouse shows that there is a developmental requirement for cholinergic transmission, for the acquisition of normal flexor/extensor and left/right coordination (Myers et al., 2005). Here, we use the developing motor system of Drosophila to show that early patterns of activity in an embryonic motor network are required for the normal development of coordinated movement.

Drosophila embryos hatch $20.5 \mathrm{~h}$ after fertilization and start crawling by repeated posterior-to-anterior sequences of muscle contraction (Fig. 1). However, the motor system is active well before hatching (Crisp et al., 2008). The earliest output of the motor network occurs $3.5 \mathrm{~h}$ before hatching and is revealed by

Received Jan. 20, 2011; revised March 16, 2011; accepted April 8, 2011

Author contributions: S.J.C., J.F.E., and M.B. designed research; S.J.C. and J.F.E. performed research; S.J.C. and J.F.E. contributed unpublished reagents/analytic tools; S.J.C. and J.F.E. analyzed data; S.J.C., J.F.E., and M.B. wrote the paper.

S.J.C. and J.F.E. contributed equally to this work.

We thank Matthias Landgraf and Helen Skaer for their helpful comments on this manuscript and members of the Drosophila community for their generous provision of fly stocks. This work was supported by grants from Merck Sharpe and Dohme (S.J.C.), the Wellcome Trust (M.B., J.F.E.), and the Royal Society (M.B.).

Correspondence should be addressed to either Sarah J. Crisp or Jan Felix Evers, Department of Zoology, University of Cambridge, Downing Street, Cambridge CB23EJ, United Kingdom, E-mail: sjc85@cam.ac.uk or jfe22@cam.ac.uk. DOI:10.1523/JNEUROSCI.0346-11.2011

Copyright $\odot 2011$ the authors $\quad 0270-6474 / 11 / 3110445-06 \$ 15.00 / 0$ repeated episodes of frequent muscle contractions (episodic activity). Over the subsequent $75 \mathrm{~min}$, motor sequences within episodes develop from being disorganized to showing elements of coordination, including left-right synchrony and sequential activation of segmental muscles in neighboring segments. The first complete posterior-to-anterior sequences of muscle contractions characteristic of motor output during larval crawling appear $2 \mathrm{~h}$ and $15 \mathrm{~min}$ before hatching $(15 \pm 1 \mathrm{~min}$ before tracheal filling [BTF]).

This gradual emergence of coordination might reflect a requirement for early activity for normal maturation and refinement of motor circuitry. Alternatively, activity in the motor network might start before circuits are complete. If that were the case, then activity might not be essential, but simply incidental to further growth and addition of circuit components that are required before properly coordinated motor output can begin. To distinguish between these alternatives, we altered the pattern of activity in the embryonic network by a series of loss- and gain-offunction experiments.

\section{Materials and Methods}

Flies. Flies carrying GFP traps G203 and ZCL2144, UAS-shits1, UAS-ChR2, UAS-TNT-G, UAS-TNT-VIF, PO163-GAL4, elav-GAL4, and OK371-GAL4 were recombined and crossed to generate embryos of the following genotypes: w;G203/UAS-shits1 ${ }^{\text {ts }}$ G203;ZCL2144, w;OK371-GAL4, G203/G203; ZCL2144/UAS-shits ${ }^{\text {ts }}$, ZCL2144, elav-GAL4/+;G203;ZCL2144/UAS-shits1, ZCL2144, w;UAS-TNT-G, G203/G203; ZCL2144/PO163-GAL4, ZCL2144, w;UAS-TNT-VIF, G203/G203;ZCL2144/PO163-GAL4, ZCL2144, w;UASChR2/+;UAS-ChR2/PO163-GAL4, elav-GAL4/+;UAS-ChR2/+;UASChR2/+ and elav-GAL4/+;/UAS-shits ${ }^{\text {ts }}$ UAS-ChR2/+;UAS-ChR2/+.UAS$s h i^{t s 1}$ embryos were raised at $20^{\circ} \mathrm{C}$, other embryos at $25^{\circ} \mathrm{C}$. Parental flies were fed yeast paste containing all-trans retinal $(100 \mu \mathrm{M})$ for $2 \mathrm{~d}$ before collection of embryos carrying ChR2. ChR2 embryos were raised in darkness before experiments.

Imaging. Embryos of either sex carrying muscle markers G203 and ZCL2144 were placed in water between a gas-permeable membrane (BioFolie, Grenier) and a cover glass. Ventral longitudinal muscle contractions were visualized by spinning disc confocal microscopy, recorded and 
analyzed as previously described (Crisp et al., 2008). In other experiments, embryos of either sex were imaged on an Olympus BX51 WI microscope $(\times 10$ objective) using transmitted light from below. Images were captured with a CCD camera, displayed, and recorded in MetaMorph (Version 7.0r04), and the resulting images (TIFF format) converted into movies (AVI format) using GraphicConverter X (Version 5.7.3, Lemke Software GmbH). Denticle band movements in late embryos [ $>18.5 \mathrm{~h}$ after egg laying (AEL)] were recorded using a Leica M420 macroscope, JVC TK-C1380 video camera and Sony digital videocassette recorder DSR-309.

Temperature control. Temperature was controlled with a thermoelectric controller (MTTC1410, Melcor) using a thin-film Pt1000 temperature probe positioned next to the embryo and a sealed Peltier device in contact with the cover glass. GFPtagged muscles could not be imaged before $16.5 \mathrm{~h}$ AEL, and such embryos were temperature-shifted in an incubator before muscle imaging after return to the permissive temperature $\left(20-22^{\circ} \mathrm{C}\right)$.

Light stimulation. Light pulses (20 ms; minimum required for contractile responses in late embryos expressing ChR2) of specific wavelengths were delivered at $1 \mathrm{~Hz}$ (to avoid synaptic rundown) using a stimulator (Master-8, A.M.P.I.) to control the interlock on the acousto-optic tunable filter of a $488 \mathrm{~nm}$ laser (Melles-Griot, 534-A-A03). Embryos were imaged without activating ChR2, by illuminating with long-pass-filtered visible light (Thorlabs long-pass filter [ $>550 \mathrm{~nm}])$.

Statistics. Data were tested for normality (Shapiro-Wilk test) and homogeneity (Levene's test). Statistical comparisons were made by ANOVA and Tukey's HSD post hoc analysis for multiple comparisons and otherwise by Student's $t$ test. Data are reported as mean \pm SEM. All statistical tests were performed with $\mathrm{R}$ (R-project).

\section{Results}

Blocking synaptic transmission delays the onset of coordination

Our first approach was to block synaptic transmission reversibly as motor circuits developed by targeting the expression of a temperature-sensitive, dominant-negative form of the essential vesicle recycling protein Shibire $\left(\mathrm{Shi}^{\mathrm{isl}}\right)$ to all neurons (elavGAL4) (Kitamoto, 2001). Motor output was monitored before, during, and after experimental manipulation by recording contraction/relaxation cycles of specific muscles.

When synaptic transmission is blocked in all neurons by holding embryos at the restrictive temperature $\left(30^{\circ} \mathrm{C}\right)$, they show no sign of their usual episodic activity. Episodic activity resumes (after a delay) when embryos are returned to room temperature $\left(22^{\circ} \mathrm{C}\right)$. When we raise such embryos at $30^{\circ} \mathrm{C}$ for $2 \mathrm{~h}$, from before activity in motor circuits can be recorded until after coordinated crawling-like sequences normally emerge (105 min BTF to 15 min after tracheal filling [ATF]), the appearance of coordinated movements is delayed (Fig. $2 \mathrm{~A}$ ). After

B

Ci

Cii

Ciii

Civ
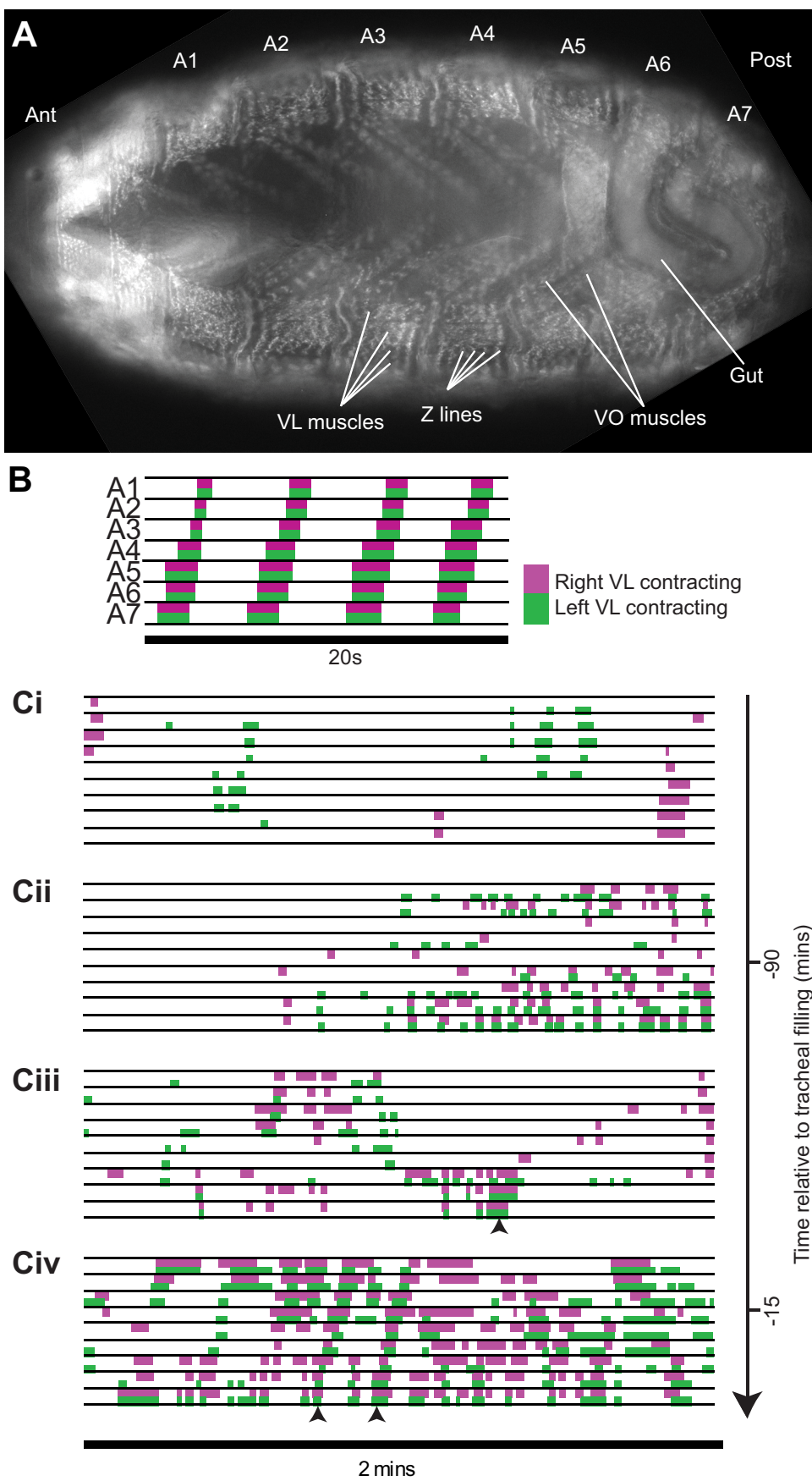

Figure 1. Embryonic motor output. A, Ventral view of embryo carrying GFP traps expressed at muscle Z-lines. Muscles (VL, ventral longitudinal muscles; V0, ventral oblique muscles) can be individually identified (Bate, 1993) in abdominal segments A1-A7. Muscle contractions are recorded by monitoring Z-line displacement. $\boldsymbol{B}$, Hatched larvae move by peristaltic waves of contraction, spreading from posterior to anterior. $C$, The developmental sequence of motor output in the embryo. Before 75 min BTF, muscle contractions are myogenic, spreading along the right or left side of the embryo ( $C$ i). Neurally driven bursts of uncoordinated contractions begin 75 min BTF (Cii). Subsequent bursts contain partial waves of contraction (Ciii, arrowhead). Fifteen minutes BTF, the first complete sequences of posterior-to-anterior contraction occur (Civ, arrowheads).

return to $22^{\circ} \mathrm{C}(16 \pm 4 \mathrm{~min})$, the embryos begin to show uncoordinated episodic activity, but the first coordinated sequences only appear after $55 \pm 4 \mathrm{~min}$. In comparison, when we block synaptic transmission in embryos for just $1 \mathrm{~h}$ ( $45 \mathrm{~min}$ BTF to 15 min ATF), while the delay in resuming uncoordinated episodic activity is similar (15 $\pm 4 \mathrm{~min})$, the first coordinated wave of contraction emerges significantly earlier at $31 \pm 2 \min (p<0.01)$. When we inhibit synaptic transmission after the first coordinated 
A
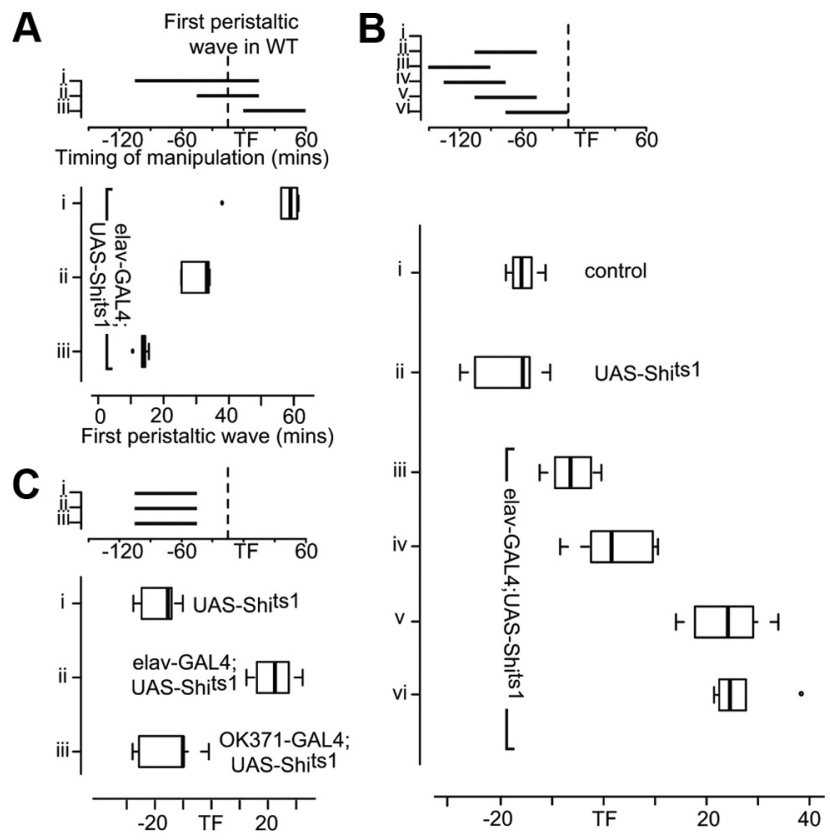

Figure 2. Blocking synaptic transmission delays the onset of coordinated movements. Top panels indicate time of heating to $30^{\circ} \mathrm{C}$ for each experimental group. $A$, Time to first coordinated sequence in embryos expressing shit ${ }^{\text {ts }}$ in all neurons (elav-GAL4;UAS-shis ${ }^{\text {ts }} ; n=5$ in each group) after return to permissive temperature. $\boldsymbol{B}$, Time of first coordinated sequence of contractions in embryos expressing $\mathrm{sh}^{\text {it } 1}$ in all neurons ( $n=5$ in each group) compared with controls ( $n=5$ for UAS-shits ${ }^{i t}$ alone; $n=8$ for $w ; G 203 ; Z C L 2144$ ). C, Time of first coordinated sequence in embryos expressing shits ${ }^{\text {t }}$ in motor neurons $(n=5)$. Data are shown as box-and-whisker plots; whiskers, smallest and largest observation; box, 1st and 3rd quartile; middle bar, median; circles, outliers.

movements (TF-60 min ATF), embryos resume crawling-like sequences of contraction after $14 \pm 1 \mathrm{~min}$ (within the first episode of motor output; $p<0.01$ ). These data suggest that a threshold amount of neuronal activity is needed before coordinated sequences can emerge. However, once neuronal circuits are set up to produce coordinated output, blocking synaptic transmission does not affect the resumption of normal function once the block is removed.

Consistent with this idea, the onset of coordinated motor activity is only marginally, if at all, delayed $(8 \pm 2 \mathrm{~min}$ BTF $)$ when synaptic transmission is blocked for $1 \mathrm{~h}$ before the normal onset of uncoordinated episodic activity (135-75 min BTF) (Fig. 2 B). However, imposing this synaptic block $15 \mathrm{~min}$ later in development (120-60 min BTF) so that the first 15 min of episodic motor activity are suppressed delays coordinated motor output by $\sim 15 \min (1 \pm 4 \min$ ATF; $p<0.01)$. Most strikingly, when we block synaptic transmission for $1 \mathrm{~h}$ after the onset of episodic activity but before the normal onset of coordinated motor output (90-30 min and 75-15 min BTF), crawling-like sequences are severely delayed, by $\sim 40 \mathrm{~min}(22 \pm 4 \mathrm{~min}$ ATF and $25 \pm 3 \mathrm{~min}$ ATF, respectively; $p<0.01)$. We conclude that there is a sensitive period, from the onset of motor output until the first coordinated sequences emerge, when release of neurotransmitter is required for the normal development of motor circuits.

\section{The role of sensory input}

Next, we asked whether movement itself contributes to the sensitive phase of development (Fig. 2C). When Shi ${ }^{\text {tsl }}$ expression is targeted to motor neurons alone (OK371-GAL4) (Mahr and Aberle, 2006), as expected, episodic motor activity, as revealed by muscle contractions, is abolished at $30^{\circ} \mathrm{C}$ but resumes on return to the permissive

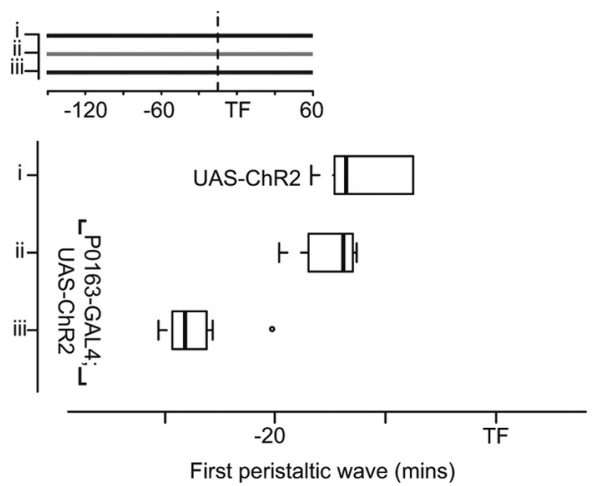

Figure 3. Sensory input influences the onset of coordination. Time of first coordinated sequence is shown. Two control groups were imaged: (i) embryos carrying UAS-ChR2 but no GAL4 driver, exposed to $488 \mathrm{~nm}$ light at $1 \mathrm{~Hz}$, (ii) P0163-GAL4;UAS-ChR2 embryos exposed to longer wavelengths of light of comparable intensity. iii, Experimental embryos with stimulated (488 $\mathrm{nm}, 1 \mathrm{~Hz}$ ) ChR2 expressed in sensory neurons ( $n=7)$. Insert shows wavelength of light used in each experiment (black, $488 \mathrm{~nm}$; gray, longer wavelength light).

temperature. However, the absence of neurally driven movement during the sensitive period has no effect on the subsequent emergence of coordinated sequences, which appear on schedule once the block is removed ( $15 \pm 4 \mathrm{~min} \mathrm{BTF})$. We conclude that patterned sensory input in response to early, immature movement sequences does not contribute directly to the maturation of central networks and the beginnings of coordination. This matches the earlier finding that central pattern-generating circuits underlying larval crawling can assemble in the complete absence of sensory input during embryonic development (Suster and Bate, 2002).

We have previously reported that in embryos lacking all sensory input, motor episodes are less frequent, and the onset of coordinated sequences is delayed by $\sim 1 \mathrm{~h}$, compared with controls (Crisp et al., 2008). This reduction in episode frequency suggests that in normal embryos input from sensory neurons contributes to levels of excitation centrally, which in turn determine the interval between episodes and hence the length of time before coordination first appears. To test this idea further, we targeted expression of the light-activated cation channel ChR2 (Boyden et al., 2005; Schroll et al., 2006) to sensory neurons (PO163-GAL4) (Hummel et al., 2000), and stimulated with 20 ms pulses of $488 \mathrm{~nm}$ light at $1 \mathrm{~Hz}$ to increase firing in sensory neurons. Episodic motor activity begins on schedule in embryos with enhanced sensory activity, just as it does in embryos lacking all sensory input (Crisp et al., 2008) (91 \pm 3 min BTF; $89 \pm 3$ min BTF in controls, not significant). However, episodes are now more frequent $(11 \pm 4$ min episode interval compared with $14 \pm$ 6 min in controls; $p<0.01)$ and coordinated sequences begin 12 min earlier $(27 \pm 1$ min BTF; $p<0.01)$ than in controls (Fig. 3).

From these experiments, we conclude that input from sensory neurons influences the frequency of episodes generated by the immature motor network. Furthermore, when the frequency is increased, the onset of coordination is brought forward, and when the frequency declines, the onset of coordination is delayed. This provides independent evidence for our conclusion that activity is essential for the normal maturation of the motor network and for the view that a threshold level of activity must have occurred before coordination can emerge.

\section{Abnormal patterns of activity delay the onset of coordinated movement}

In the vertebrate visual system, neural activity itself is not sufficient to adjust forming connections; it is the pattern of activity 
A
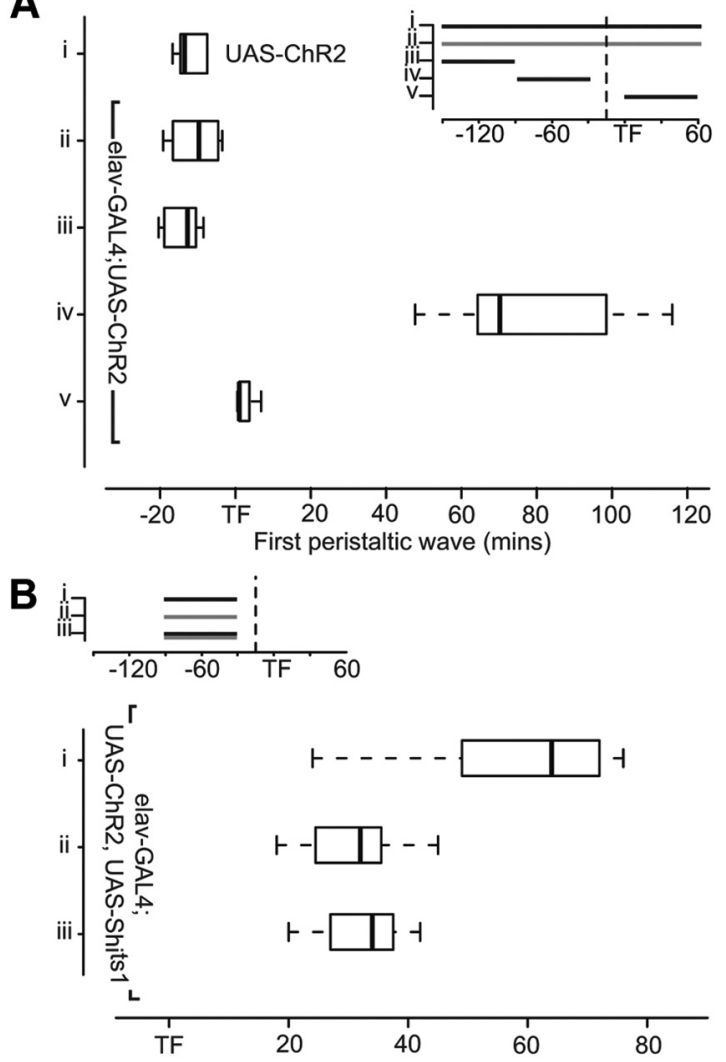

Figure 4. Stimulation during the sensitive period delays or prevents the onset of coordinated movements. $\boldsymbol{A}$, Two control groups were imaged: (i) UAS-ChR2, no GAL4 driver $(n=6)$, (ii) elav-GAL4;UAS-ChR2 long wavelength light. Stimulation before (iii) the sensitive period has no effect. iv, Two of 8 embryos stimulated during the sensitive period showed no coordinated sequences and did not hatch. The remaining 6 embryos displayed severely delayed onset of coordinated muscle contraction. $\boldsymbol{v}$, Embryos execute coordinated sequences throughout stimulation after the sensitive period (TF-60 min ATF). B, UAS-ChR2 and UAS-shits ${ }^{\text {t }}$ in all neurons. Embryos were (i) stimulated with $488 \mathrm{~nm}$ light, (ii) held at restrictive temperature, or (iii) received $488 \mathrm{~nm}$ stimulus at restrictive temperature $90-30 \min \mathrm{BTF}(n=7)$.

that determines whether particular connections will be retained or withdrawn. Either the absence of activity or the simultaneous activation of all neurons (for example, by stroboscopic illumination [Schmidt and Buzzard, 1993; Brickley et al., 1998]) leads to the formation of a poorly organized visual map. While the data we have presented so far all point to a requirement for early activity in the normal development of motor circuitry, it is unclear whether this is a requirement for activity itself or whether the pattern of activity that precedes coordination is important for the final maturation of the motor network.

To distinguish between these alternatives, we superimposed a correlated pattern of activity across the developing nervous system. Embryos expressing ChR2 in all neurons (elav-Gal4;UASChR2) were subjected to $1 \mathrm{~h}$ of stimulation using $20 \mathrm{~ms}$ light pulses at $1 \mathrm{~Hz}$ as before. Embryonic movements were recorded during stimulation and for up to $4 \mathrm{~h}$ afterward. We varied the period of stimulation so that neurons were excited either before (150-90 min BTF), during (90-30 BTF), or after (TF-60 min ATF) the sensitive period identified by blocking synaptic transmission. When neurons are excited synchronously during the sensitive period for $1 \mathrm{~h}$, there is a profound effect on the development of motor output in every case. In 6 of 8 embryos, the first appearance of coordinated movements was severely delayed $(78 \pm 10 \min$ ATF; $p<0.01)$ (Fig. 4). Nonetheless, these embryos

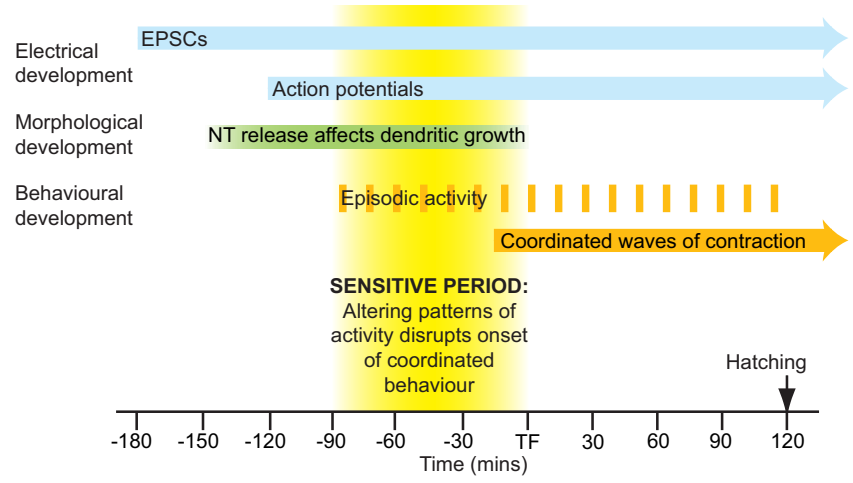

Figure 5. Timeline of motor system development in Drosophila. Summary diagram showing sequence of electrical (Baines and Bate, 1998), morphological (Tripodi et al., 2008), and behavioral development (Crisp et al., 2008). Times are relative to tracheal filling (TF $=0$ ). NT, neurotransmitter. Vertical bars indicate episodic activity in the motor system as revealed by muscle contractions.

hatched and crawled on agar plates. However, 2 of the 8 experimental embryos never produced coordinated peristaltic waves and failed to hatch. These effects are only seen when stimulation occurs during the sensitive period of development, when the onset of coordination can be delayed by blocking activity in the network. Since synchronized stimulation is as effective in delaying or preventing the onset of coordination as blocking activity, we conclude that patterned activation of neurons is required during this developmental window for the normal appearance of coordinated output.

If circuit development is impeded by altering normal patterns of synaptic transmission between neurons, it should be possible to rescue these detrimental effects by blocking synaptic transmission during the period of stimulation. To do this, we made flies expressing both ChR2 and Shi ${ }^{\text {ts1 }}$ in all neurons and then held embryos at the restrictive temperature while stimulating with $488 \mathrm{~nm}$ light during the sensitive period. When these embryos receive the light stimulus alone, there is the expected long delay in the onset of coordinated movement ( $59 \pm 6 \mathrm{~min} \mathrm{ATF})$. When synaptic transmission alone is blocked, coordinated movement is delayed less ( $31 \pm 3$ min ATF; $p<0.01)$. When the two manipulations are combined, coordinated movement is no more delayed than when synaptic transmission is blocked alone ( $32 \pm 3 \mathrm{~min}$ ATF). Thus, the extended delay associated with light stimulation fails to occur if synaptic transmission is blocked. We conclude that disruption to normal development of motor coordination associated with correlated activation of the whole network is driven, at least in part, by abnormal patterns of synaptic signaling.

\section{Discussion}

Many parts of the nervous system become active before development is complete (Blankenship and Feller, 2010). Characteristically, this activity is episodic, and it could be that the repetitive firing of ensembles of developing neurons is a trivial consequence of their progressive acquisition of excitable properties and the development of connections between them. In vertebrates, however, there is considerable evidence that neuronal activity during development, both spontaneous and driven by environmental stimuli, contributes to the normal maturation of sensory systems. During this phase of tuning and modification, maps are refined, resolution increases, patterns of terminal segregation and coconnection are determined, and circuitry is adjusted to meet change imposed by differential patterns of growth (Kobayashi et al., 1990; Kaethner and Stuermer, 1994; Gnuegge et al., 2001; McLaughlin et 
al., 2003; Sanes et al., 2006). It might be thought that the functional characteristics of motor systems, which are networks capable of orchestrating the coordinated firing of multiple outputs underlying patterned movement, would also require tuning and adjustment in the final stages of their maturation. Indeed, the widespread occurrence of early activity in motor networks including the spinal cord is a tantalizing hint that this is indeed the case (Landmesser and O’Donovan, 1984; van Mier et al., 1989; Reynolds et al., 1998; Saint-Amant and Drapeau, 1998; Clarac et al., 2004). However, there is an essential difference between the spatial organization of sensory and motor systems, namely that sensory systems are commonly organized to form maps, whereas motor networks consist of distributed elements linked to form circuits that have no obvious morphological correlate (Boyden et al., 2005; Sanes et al., 2006; Goulding, 2009; Roberts et al., 2010). This organizational difference has hampered investigation and raises the issue of whether in fact there is a requirement in such a distributed system for an analogous process of refinement as the network matures and becomes functional.

Drosophila is well known for its rapid development and for the relatively small number of supposedly stereotyped neurons that compose its nervous system. It seemed likely, therefore, that if an activity-independent system of growth and connection were sufficient to wire a motor network capable of generating coordinated outputs, the Drosophila embryo would demonstrate this. However, our investigation reveals something very different: the first outputs of the embryonic motor system are poorly organized, coordinated outputs only appear after a further hour of episodic bursting, and this activity appears to be essential for the normal development of the motor network (Fig. 5).

Even in the simpler nervous systems of arthropods, like Drosophila, there is abundant evidence that connectivity and physiological characteristics of constituent neurons depend on developmental processes that are exploratory and plastic rather than preprogrammed and specific. Branching patterns between equivalent neurons in isogenic arthropods (Levinthal et al., 1976) and equivalent neurons on left and right sides of the same animal (Burrows, 1973; Goodman, 1978) differ considerably. Since these branches are the sites of synaptic contacts (Pearson and Goodman, 1979), we may conclude that there are different growth solutions to generating the same functional connectivity. Thus, final patterns of growth and connection appear to be subject to some homeostatic control that detects and stabilizes a functionally adequate pattern of connections when it is achieved. Indeed, we now have evidence that the growth of dendritic arborizations in embryonic motor neurons in Drosophila is homeostatically regulated, in part by transmitter release from their presynaptic partners as the developing nervous system first becomes active (Tripodi et al., 2008) (Fig. 5). In a similar way, it has become clear both from experimental observations and from modeling studies that various different combinations of ionic conductance densities can generate the same excitable characteristics in equivalent neurons in different individuals (Golowasch et al., 1999; Soto-Trevino et al., 2001; Prinz et al., 2004). It seems, therefore, that actual levels of excitability are set as neurons explore alternative combinations of ion channel expression until some target level of activity is achieved. Actual levels of activity for individual neurons will depend both on their intrinsic ion channel mix and the levels of synaptic input they experience, and in Drosophila, it has been shown that central neurons adjust their intrinsic excitability in response to actual levels of synaptic excitation received (Baines et al., 2001; Baines, 2003). Although these experiments were performed in part with larval neurons, it is likely that these mechanisms for activity- dependent adjustment will operate as the electrical properties of neurons mature and they and their synaptic partners become active for the first time. Thus, both connectivity and excitability are likely to be responsive to early network activity. Our results show that there is indeed a sensitive period in the development of motor coordination which coincides with the very first bursts of activity that are generated in the motor circuitry as synapses form and the network matures (Fig. 5).

Recent work in vertebrate motor systems has shown that altering levels of activity during early development disrupts neurotransmitter specification (Borodinsky et al., 2004) and axonal pathfinding (Kastanenka and Landmesser, 2010). Here, we speculate that endogenous patterns of synaptic transmission in the embryonic nervous system of Drosophila form part of a general mechanism whereby functional characteristics of immature motor networks are modified and adjusted to allow for the normal development of coordinated patterns of movement. Precisely how individual neurons in a developing network extract information from patterns of activity and translate it into structural or functional changes can now be investigated. The developing motor circuitry of Drosophila, with its relative simplicity, provides a unique opportunity to reveal the mechanisms of activitydependent modifications occurring at the level of individual synapses between identified neurons and importantly to relate them to the behavioral outcome.

\section{References}

Baines RA (2003) Postsynaptic protein kinase A reduces neuronal excitability in response to increased synaptic excitation in the Drosophila CNS. J Neurosci 23:8664-8672.

Baines RA, Bate M (1998) Electrophysiological development of central neurons in the Drosophila embryo. J Neurosci 18:4673-4683.

Baines RA, Uhler JP, Thompson A, Sweeney ST, Bate M (2001) Altered electrical properties in Drosophila neurons developing without synaptic transmission. J Neurosci 21:1523-1531.

Bate M (1993) The mesoderm and its derivatives. In: The Development of Drosophila melanogaster (Bate M, Martinez-Arias A, eds), pp 1013-1090: Cold Spring Habor Laboratory Press.

Blankenship AG, Feller MB (2010) Mechanisms underlying spontaneous patterned activity in developing neural circuits. Nat Rev Neurosci 11:18-29.

Borodinsky LN, Root CM, Cronin JA, Sann SB, Gu X, Spitzer NC (2004) Activity-dependent homeostatic specification of transmitter expression in embryonic neurons. Nature 429:523-530.

Boyden ES, Zhang F, Bamberg E, Nagel G, Deisseroth K (2005) Millisecondtimescale, genetically targeted optical control of neural activity. Nat Neurosci 8:1263-1268.

Brickley SG, Dawes EA, Keating MJ, Grant S (1998) Synchronizing retinal activity in both eyes disrupts binocular map development in the optic tectum. J Neurosci 18:1491-1504.

Burrows M (1973) The morphology of an elevator and a depressor motorneuron in the hindwing of a locust. J Comp Physiol A Neuroethol Sens Neural Behav Physiol 184:141-166.

Clarac F, Pearlstein E, Pflieger JF, Vinay L (2004) The in vitro neonatal rat spinal cord preparation: a new insight into mammalian locomotor mechanisms. J Comp Physiol A Neuroethol Sens Neural Behav Physiol 190:343-357.

Crisp S, Evers JF, Fiala A, Bate M (2008) The development of motor coordination in Drosophila embryos. Development 135:3707-3717.

Gnuegge L, Schmid S, Neuhauss SC (2001) Analysis of the activity-deprived zebrafish mutant macho reveals an essential requirement of neuronal activity for the development of a fine-grained visuotopic map. J Neurosci 21:3542-3548.

Golowasch J, Abbott LF, Marder E (1999) Activity-dependent regulation of potassium currents in an identified neuron of the stomatogastric ganglion of the crab Cancer borealis. J Neurosci 19:RC33.

Goodman CS (1978) Isogenic grasshoppers: genetic variability in the morphology of identified neurons. J Comp Neurol 182:681-705.

Goulding M (2009) Circuits controlling vertebrate locomotion: moving in a new direction. Nat Rev Neurosci 10:507-518. 
Harrison RG (1904) An experimental study of the relation of the nervous system to the developing musculature in the embryo of the frog. Am J Anat 3:197-220.

Haverkamp LJ (1986) Anatomical and physiological development of the Xenopus embryonic motor system in the absence of neural activity. J Neurosci 6:1338-1348.

Haverkamp LJ, Oppenheim RW (1986) Behavioral development in the absence of neural activity: effects of chronic immobilization on amphibian embryos. J Neurosci 6:1332-1337.

Hummel T, Krukkert K, Roos J, Davis G, Klämbt C (2000) Drosophila Futsch/22C10 is a MAP1B-like protein required for dendritic and axonal development. Neuron 26:357-370.

Kaethner RJ, Stuermer CA (1994) Growth behavior of retinotectal axons in live zebrafish embryos under TTX-induced neural impulse blockade. J Neurobiol 25:781-796.

Kastanenka KV, Landmesser LT (2010) In vivo activation of channelrhodopsin-2 reveals that normal patterns of spontaneous activity are required for motoneuron guidance and maintenance of guidance molecules. J Neurosci 30:10575-10585.

Kitamoto T (2001) Conditional modification of behavior in Drosophila by targeted expression of a temperature-sensitive shibire allele in defined neurons. J Neurobiol 47:81-92.

Kobayashi T, Nakamura H, Yasuda M (1990) Disturbance of refinement of retinotectal projection in chick embryos by tetrodotoxin and grayanotoxin. Brain Res Dev Brain Res 57:29-35.

Landmesser LT, O’Donovan MJ (1984) Activation patterns of embryonic chick hind limb muscles recorded in ovo and in an isolated spinal cord preparation. J Physiol 347:189-204.

Levinthal F, Macagno E, Levinthal C (1976) Anatomy and development of identified cells in isogenic organisms. Cold Spring Harb Symp Quant Biol 40:321-331.

Mahr A, Aberle H (2006) The expression pattern of the Drosophila vesicular glutamate transporter: a marker protein for motoneurons and glutamatergic centers in the brain. Gene Expr Patterns 6:299-309.

McLaughlin T, Torborg CL, Feller MB, O'Leary DD (2003) Retinotopic map refinement requires spontaneous retinal waves during a brief critical period of development. Neuron 40:1147-1160.

Myers CP, Lewcock JW, Hanson MG, Gosgnach S, Aimone JB, Gage FH, Lee KF, Landmesser LT, Pfaff SL (2005) Cholinergic input is required dur- ing embryonic development to mediate proper assembly of spinal locomotor circuits. Neuron 46:37-49.

Pearson KG, Goodman CS (1979) Correlation of variability in structure with variability in synaptic connections of an identified interneuron in locusts. J Comp Neurol 184:141-166.

Prinz AA, Bucher D, Marder E (2004) Similar network activity from disparate circuit parameters. Nat Neurosci 7:1345-1352.

Reynolds SA, French KA, Baader A, Kristan WB Jr (1998) Development of spontaneous and evoked behaviors in the medicinal leech. J Comp Neurol 402:168-180.

Roberts A, Li WC, Soffe SR (2010) How neurons generate behavior in a hatchling amphibian tadpole: an outline. Front Behav Neurosci 4:16.

Saint-Amant L, Drapeau P (1998) Time course of the development of motor behaviors in the zebrafish embryo. J Neurobiol 37:622-632.

Sanes DH, Reh TA, Harris WA (2006) Development of the Nervous System, Ed 2. Oxford: Elsevier Academic Press.

Schmidt JT, Buzzard M (1993) Activity-driven sharpening of the retinotectal projection in goldfish: development under stroboscopic illumination prevents sharpening. J Neurobiol 24:384-399.

Schroll C, Riemensperger T, Bucher D, Ehmer J, Völler T, Erbguth K, Gerber B, Hendel T, Nagel G, Buchner E, Fiala A (2006) Light-induced activation of distinct modulatory neurons triggers appetitive or aversive learning in Drosophila larvae. Curr Biol 16:1741-1747.

Soto-Treviño C, Thoroughman KA, Marder E, Abbott LF (2001) Activitydependent modification of inhibitory synapses in models of rhythmic neural networks. Nat Neurosci 4:297-303.

Stafford BK, Sher A, Litke AM, Feldheim DA (2009) Spatial-temporal patterns of retinal waves underlying activity-dependent refinement of retinofugal projections. Neuron 64:200-212.

Suster ML, Bate M (2002) Embryonic assembly of a central pattern generator without sensory input. Nature 416:174-178.

Tripodi M, Evers JF, Mauss A, Bate M, Landgraf M (2008) Structural homeostasis: compensatory adjustments of dendritic arbor geometry in response to variations of synaptic input. PLoS Biol 6:e260.

van Mier P, Armstrong J, Roberts A (1989) Development of early swimming in Xenopus laevis embryos: myotomal musculature, its innervation and activation. Neuroscience 32:113-126. 